\title{
Gas Exchange in the Prone Posture
}

\author{
Nicholas J Johnson MD, Andrew M Luks MD, and Robb W Glenny MD
}

\author{
Introduction \\ Overview of Gas Exchange \\ Lung Structure \\ Normal Exchange of Oxygen and Carbon Dioxide \\ Abnormal Exchange of Oxygen and Carbon Dioxide \\ Gas Exchange in the Prone Posture Under Normal Conditions \\ Spatial Distribution of Ventilation \\ Spatial Distribution of Perfusion \\ Ventilation and Perfusion Matching \\ Mechanisms by Which the Prone Posture Improves Gas Exchange in \\ Animal Models of ARDS \\ Additional Physiologic Effects of the Prone Posture \\ Clinical Trials \\ Summary
}

\begin{abstract}
The prone posture is known to have numerous effects on gas exchange, both under normal conditions and in patients with ARDS. Clinical studies have consistently demonstrated improvements in oxygenation, and a multi-center randomized trial found that, when implemented within $48 \mathrm{~h}$ of moderate-to-severe ARDS, placing subjects in the prone posture decreased mortality. Improvements in gas exchange occur via several mechanisms: alterations in the distribution of alveolar ventilation, redistribution of blood flow, improved matching of local ventilation and perfusion, and reduction in regions of low ventilation/perfusion ratios. Ventilation heterogeneity is reduced in the prone posture due to more uniform alveolar size secondary to a more uniform vertical pleural pressure gradient. The prone posture results in more uniform pulmonary blood flow when compared with the supine posture, due to an anatomical bias for greater blood flow to dorsal lung regions. Because both ventilation and perfusion heterogeneity decrease in the prone posture, gas exchange improves. Other benefits include a more uniform distribution of alveolar stress, relief of left-lower-lobe lung compression by the heart, enhanced secretion clearance, and favorable rightventricular and systemic hemodynamics. Key words: prone; acute respiratory distress syndrome; ARDS; respiratory failure; gas exchange; respiratory physiology. [Respir Care 2017;62(8):1097-1110. (C) 2017 Daedalus Enterprises]
\end{abstract}

\section{Introduction}

The prone posture has been used for more than 40 years to treat patients with severe ARDS. ${ }^{1-3}$ The effects of the prone posture on gas exchange are complex and related to alterations in the distribution of alveolar ventilation and blood flow, improved matching of local ventilation and perfusion, and reduction in regions of low ventilation/per- fusion ratios.1,4-6 Other benefits include a more uniform distribution of alveolar stress, enhanced secretion clearance, and favorable right-ventricular and systemic hemodynamics. A number of early trials demonstrated that the prone posture improves gas exchange, but none documented a mortality benefit. ${ }^{7-12}$ A multi-center randomized trial found that, when implemented within $48 \mathrm{~h}$ of moderateto-severe hypoxemia due to ARDS, ventilation in the prone 
posture decreased both 28 - and 90-d mortality and increased ventilator-free days. ${ }^{13}$ As a result, there has been a growing interest in this intervention for treatment of ARDS patients with significant hypoxemia.

In this article, we describe the effects of prone posture on gas exchange. We begin by reviewing the principles of gas exchange, including normal physiology and pathologic alterations independent of posture, and then discuss the physiologic basis for improved gas exchange in the prone posture. We conclude by discussing other physiologic benefits of ventilation in the prone posture and reviewing data from clinical trials on the effects of prone posture on gas exchange.

\section{Overview of Gas Exchange}

\section{Lung Structure}

The lung's structure facilitates efficient exchange of respiratory gases. Air enters the adult trachea with a crosssectional area of roughly $3 \mathrm{~cm}^{2}$ and is delivered through repeated generations of bifurcating airways to the alveoli, which, in total, have a surface area of $\sim 140 \mathrm{~m}^{2}$, roughly the size of a tennis court. ${ }^{14,15}$ The pulmonary vasculature follows a similar pattern, branching in tandem with the airways from the main pulmonary artery all the way down to the capillaries, which cover $85-95 \%$ of the alveolar surface. Under normal conditions, gases diffuse easily across the exceptionally thin barrier $(\sim 1 \mu \mathrm{m})$ between capillary blood and the alveolar space. ${ }^{14,16}$

\section{Normal Exchange of Oxygen and Carbon Dioxide}

The exchange of $\mathrm{O}_{2}$ depends on a partial pressure gradient between alveolar gas and pulmonary capillary blood. ${ }^{14}$ In the normal lung, capillaries deliver mixed venous blood with a low $\mathrm{P}_{\mathrm{O}_{2}}\left(\mathrm{P}_{\overline{\mathrm{v}}_{2}}\right)$ to the alveolus (Fig. 1). Because the $\mathrm{P}_{\mathrm{O}_{2}}$ in the alveoli $\left(\mathrm{P}_{\mathrm{AO}_{2}}\right)$ is much higher than in the pulmonary capillary, $\mathrm{O}_{2}$ diffuses passively from the alveolar space into the blood. Under normal conditions, the $\mathrm{P}_{\mathrm{O}_{2}}$

The authors are affiliated with the Department of Medicine, and Dr Glenny is also affiliated with the Department of Physiology and Biophysics, University of Washington School of Medicine, Seattle, Washington.

Dr Johnson received research funding from National Institutes of Health Grant U01HL123008-02 and the Medic One Foundation. The authors have disclosed no conflicts of interest.

Correspondence: Nicholas J Johnson MD, Division of Emergency Medicine, Harborview Medical Center, 325 9th Avenue, Box 359702, Seattle, WA 98104. E-mail: nickj45@uw.edu.

DOI: $10.4187 /$ respcare. 05512

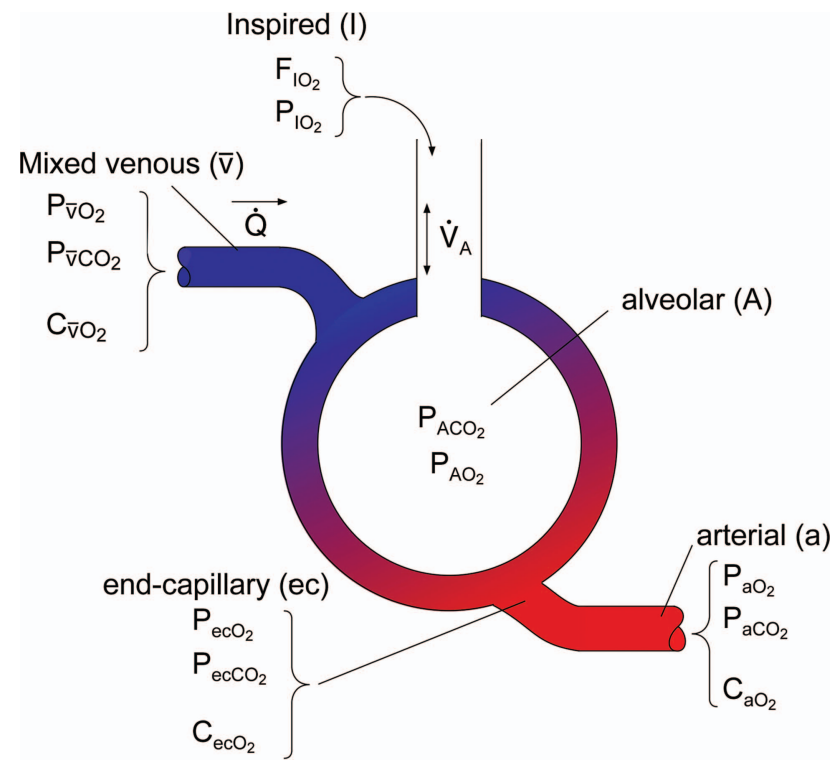

Fig. 1. A single-lung unit model with notations used for partial pressures $(P)$, gas fractions $(F)$, and content $(C)$ for oxygen for different compartments. Note that with a single-unit lung model, arterial and end-capillary values are equal.

rapidly equilibrates between the alveolar gas and pulmonary capillary blood, although there is always a small difference between the alveolar and arterial $\mathrm{O}_{2}$, referred to as the alveolar-arterial $\mathrm{O}_{2}$ difference $\left(\mathrm{P}_{(\mathrm{A}-\mathrm{a}) \mathrm{O}_{2}}\right)$ due to blood returning to the left atrium from the bronchial and thebesian veins. As will be described further below, the magnitude of the $\mathrm{P}_{(\mathrm{A}-\mathrm{a}) \mathrm{O}_{2}}$ can be used to identify cause(s) of hypoxemia in a given patient.

Exchange of $\mathrm{CO}_{2}$ follows similar principles. The partial pressure of $\mathrm{CO}_{2}\left(\mathrm{P}_{\mathrm{CO}_{2}}\right)$ is greater in mixed venous blood $\left(\mathrm{P}_{\overline{\mathrm{v} C O}}\right)$ than in the alveolar gas $\left(\mathrm{P}_{\mathrm{ACO}_{2}}\right)$, so net flow is down a pressure gradient from capillary blood to alveolar gas. Elimination of $\mathrm{CO}_{2}$ is highly efficient due to the steepness of the carbon dioxide dissociation curve in the physiologic range of partial pressures when compared with oxygen (Fig. 2).

\section{Abnormal Exchange of Oxygen and Carbon Dioxide}

Hypoxemia, defined as a low $\mathrm{P}_{\mathrm{aO}}$, can develop as a result of one of 5 different processes. The first is hypoventilation. Because $\mathrm{P}_{\mathrm{AO}_{2}}$ is determined by the ratio between the delivery to and removal of oxygen from the alveolus (alveolar ventilation $\left[\dot{\mathrm{V}}_{\mathrm{A}}\right]$ and blood flow [Q]], respectively) hypoventilation in the setting of normal cardiac output results in a globally low $\dot{\mathrm{V}}_{\mathrm{A}} / \dot{\mathrm{Q}}$ for the entire lung, which lowers $\mathrm{P}_{\mathrm{AO}_{2}}$ and, consequentially, $\mathrm{P}_{\mathrm{aO}_{2}}$. Low inspired $\mathrm{P}_{\mathrm{O}_{2}}$ typically occurs at altitude, where barometric pressure drops in the setting of a constant fraction of $\mathrm{O}_{2}$ in the air.

Diffusion limitation is a rare cause of hypoxemia in humans at rest and occurs when pulmonary blood flow is 


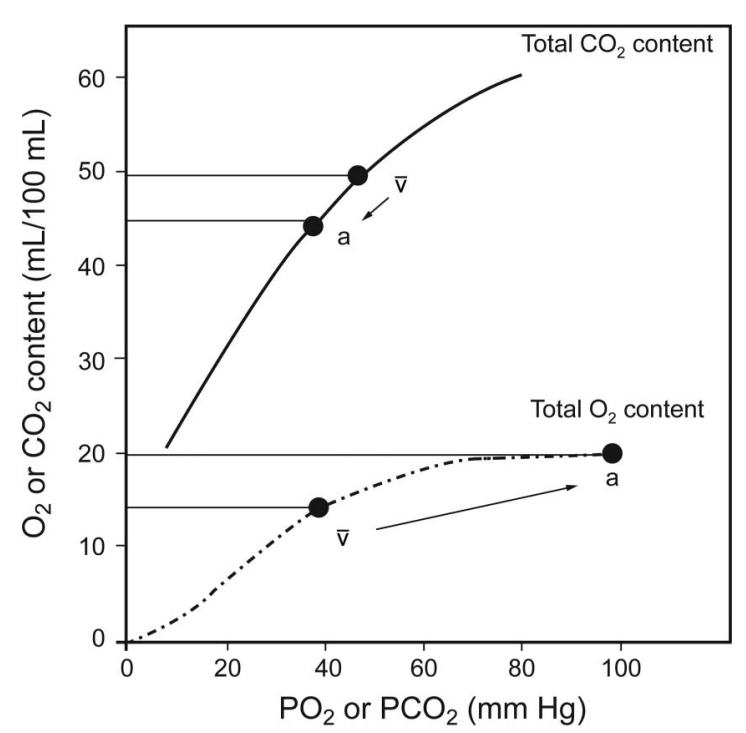

Fig. 2. Content versus partial pressure of $\mathrm{CO}_{2}$ and $\mathrm{O}_{2}$. Although the change in $\mathrm{P}_{\mathrm{CO}_{2}}$ from the venous to the arterial blood of $\sim 5$ $\mathrm{mm} \mathrm{Hg}$ is small compared with a $60-\mathrm{mm} \mathrm{Hg}$ change in $\mathrm{P}_{\mathrm{O}_{2}}$, an equivalent volume of $\mathrm{CO}_{2}$ is eliminated as $\mathrm{O}_{2}$ taken up, due to the steepness of the $\mathrm{CO}_{2}$ dissociation curve.

so rapid that the time for complete equilibration between $\mathrm{P}_{\mathrm{AO}_{2}}$ and $\mathrm{P}_{\mathrm{aO}}$ is inadequate, resulting in an increased $\mathrm{P}_{(\mathrm{A}-\mathrm{a}) \mathrm{O}_{2}}$. Diffusion limitation can be seen in high-performance athletes achieving extremely high cardiac outputs, during exercise at high altitude, and possibly in patients with idiopathic pulmonary fibrosis and a very low diffusing capacity for carbon monoxide exercising at low elevation. ${ }^{17}$

The final 2 causes of hypoxemia, low $\dot{V}_{A} / \dot{Q}$ units and shunt, are both examples of $\dot{\mathrm{V}}_{\mathrm{A}} / \dot{\mathrm{Q}}$ mismatch. When one or more lung unit has a low $\dot{\mathrm{V}}_{\mathrm{A}} / \mathrm{Q}, \mathrm{P}_{\mathrm{AO}_{2}}$ is low, leading to a decrease in the $\mathrm{P}_{\mathrm{O}_{2}}$ of end-capillary blood. Mixing welloxygenated blood from lung units with normal $\dot{\mathrm{V}}_{\mathrm{A}} / \mathrm{Q}$ ratios with poorly oxygenated blood from low $\dot{\mathrm{V}}_{\mathrm{A}} / \dot{\mathrm{Q}}$ units results in hypoxemia. The overall effect of low $\dot{\mathrm{V}}_{\mathrm{A}} / \mathrm{Q}$ units is therefore a reduced $\mathrm{P}_{a O_{2}}$ and increased $\mathrm{P}_{(\mathrm{A}-\mathrm{a}) \mathrm{O}_{2}}$. Note that this example is analogous to hypoventilation above, but in this case, it only relates to a part of the lung. Shunt can be viewed as one extreme of the range of $\dot{V}_{\mathrm{A}} / \mathrm{Q}$ ratios with a ratio of 0 (ie, perfusion without ventilation). The end-capillary $\mathrm{P}_{\mathrm{O}_{2}}$ is unchanged from mixed venous blood, because no gas exchange occurs across the alveolar-capillary barrier of such units. This blood then mixes with blood from other lung units, leading to hypoxemia and decreased arterial oxygen content. The contribution of shunt and low $\dot{\mathrm{V}}_{\mathrm{A}} / \mathrm{Q}$ regions to hypoxemia is termed venous admixture and can be quantified as the equivalent fraction of cardiac output that would be distributed to non-ventilated units $\left(\dot{\mathrm{Q}}_{\mathrm{s}} / \dot{\mathrm{Q}}_{t}\right.$, shunt fraction). As with low $\dot{\mathrm{V}}_{\mathrm{A}} / \mathrm{Q}$, the $\mathrm{P}_{(\mathrm{A}-\mathrm{a}) \mathrm{O}_{2}}$ is increased in shunt. The response to supplemental oxygen is less in shunt physiology than that seen with low $\dot{\mathrm{V}}_{\mathrm{A}} / \dot{\mathrm{Q}}$ units and varies based on the magnitude of the shunt fraction.

Dead space and wasted ventilation are key concepts for describing abnormal exchange of $\mathrm{CO}_{2}$. Dead space is defined as a lung region with ventilation but no blood flow, and wasted ventilation includes the combination of dead space and high- $\dot{\mathrm{V}}_{\mathrm{A}} / \mathrm{Q}$ regions. Total, or physiologic, dead space is composed of both anatomical and alveolar dead space, with the former referring to the conducting airways and apparatus (such as an endotracheal tube) and the latter referring to alveolar units that do not receive perfusion.

\section{Gas Exchange in the Prone Posture Under Normal Conditions}

Beyond the effect of the $\mathrm{P}_{\mathrm{O}_{2}}$ and $\mathrm{P}_{\mathrm{CO}_{2}}$ in alveolar air and mixed venous blood, gas exchange is determined by the local relationships between ventilation and blood flow, which are determined, in part, by posture. ${ }^{18}$ There are a number of mechanisms that create variability in both ventilation and blood flow at the level of gas exchange. Vertical differences in hydrostatic pressures within the vascular compartment and pleural space create regional differences in ventilation and blood flow, which are influenced by posture. Because inspired air and blood are delivered to the alveoli via structures that bifurcate repeatedly, small asymmetries in branching angles and diameters produce heterogeneous distributions of ventilation and perfusion. Additionally, alveolar and capillary pressures interact to alter the caliber of the capillary vessels within the alveolar space, thereby altering blood flow.

\section{Spatial Distribution of Ventilation}

Ventilation has long been suspected to be distributed unevenly within the lung and to be affected by changes in posture. ${ }^{18-20}$ Early studies in both humans and dogs demonstrated differences in regional alveolar gas distribution based on posture, thought to be largely due to the effect of pleural pressure gradients on alveolar size..1-23 Due to higher pleural pressures and consequently lower elastic recoil pressure of the lung, the most dependent alveoli were thought to be smaller at functional residual capacity (FRC) (Fig. 3). Because all alveoli inflate to the same size at total lung capacity, dependent alveoli receive the most ventilation on inhalation. Based on these experiments, the alveolar size hypothesis proposed that the magnitude of local ventilation is determined by the extent of inflation at the initiation of a breath, which itself is determined by the gravitationally oriented pleural pressure gradient.

Confirming the alveolar size hypothesis, a number of subsequent studies demonstrated that, if regional ventilation is normalized by alveolar tissue content, large scale ventilation becomes remarkably constant throughout the 


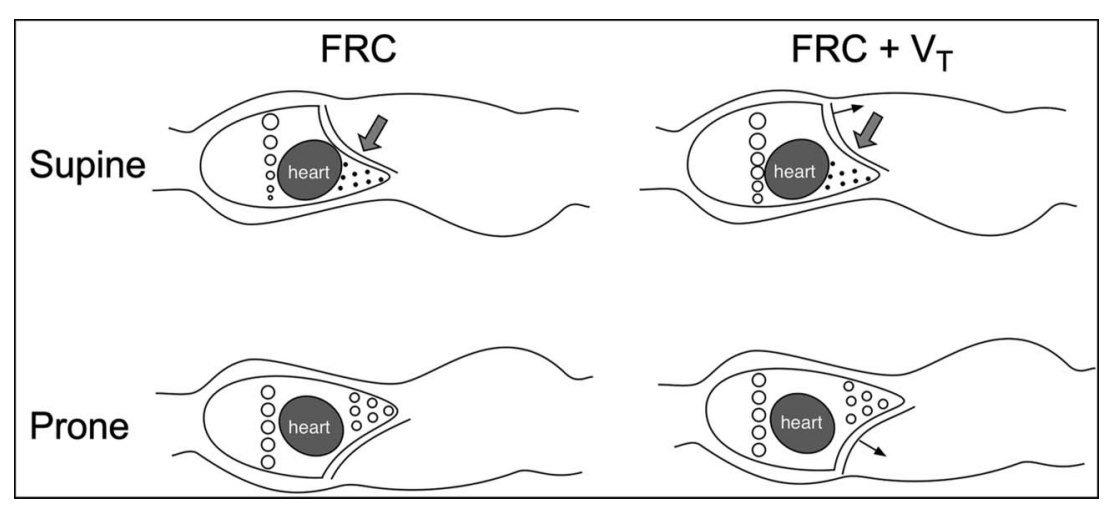

Fig. 3. The effect of prone posture on alveolar size at functional residual capacity $(F R C)$ and $F R C$ plus tidal volume $\left(V_{T}\right)$. In the supine posture, at FRC, the most dependent alveoli are small due to higher pleural pressures, compression from the heart, and extrinsic compression from abdominal contents as compared with the prone posture. During tidal breathing, the distribution of local ventilation is more uniform in the prone posture because the alveolar volumes are more uniform at the initiation of each breath.

lung, regardless of posture. ${ }^{24-26}$ The exception to the alveolar size hypothesis is found in the dorsal caudal portion of the lung in the supine posture, where the weight of the abdominal contents redistributes ventilation. If ventilation is analyzed on a per-alveolus basis, the large-scale gravitational contribution to ventilation heterogeneity is minimized, regardless of posture, with the exception of this dorsal caudal region.

Studies using more sophisticated whole-lung imaging techniques demonstrated that a much larger gradient of ventilation exists in the supine compared with the prone posture. ${ }^{27-31}$ The prone posture results in an increase of regional inflation distribution in dorsal regions and a decrease in ventral regions and a more homogeneous distribution of pleural pressure, resulting in more uniform transpulmonary pressure and regional inflation throughout the lung (Fig. 4). 4,32

A major reason for more homogeneous ventilation in the prone posture as compared with the supine posture is probably related to the distribution of lung tissue (and, consequentially, alveoli) within the thoracic cavity. A substantially greater proportion of lung tissue is contained in the dorsum of the chest. In the supine posture, approximately $20 \%$ of lung tissue is above the level of the heart, compared with $50 \%$ below the heart. ${ }^{33}$ Although some tissue mass redistributes toward the ventral portion of the chest cavity when prone, relatively less tissue mass is exposed to the compressive forces of the tissue above it. ${ }^{26}$ Additionally, the fraction of lung tissue compressed by the heart is less in the prone posture when compared with the supine posture. ${ }^{34}$ The net result is that less lung tissue and fewer alveoli in the most dependent portion of the lung are compressed by the weight of tissue above in the prone compared with the supine posture.

The weight and pressure generated by the abdominal contents influence pressure in the thoracic cavity to a greater extent in the supine than in the prone posture. When su- pine, intra-abdominal pressure greatly exceeds intrathoracic pressure, an effect that is exacerbated by obesity. 1,35,36 The highest intra-abdominal pressure is consistently measured in the dorsal regions and is transmitted to the pleural space, thus acting to compress the dorso-caudal lung regions. ${ }^{1} \mathrm{~A}$ similar effect may be seen in the prone posture when the abdomen is compressed, although the effects on gas exchange and lung and chest wall compliance are less clear. ${ }^{1,36-38}$ In an animal model of abdominal distention, Mure et $\mathrm{al}^{39}$ demonstrated that the prone posture resulted in a greater improvement in oxygenation compared with the supine posture when the animals had increased abdominal pressures.

The prone posture also results in a more uniform distribution of stress and strain because the greater mass of dorsal lung tissue is suspended along a relatively larger horizontal dorsal chest wall. ${ }^{1}$ Several authors have likened the lung to a triangular-shaped spring alternatively suspended from either its apex (supine posture) or its base (prone posture) (Fig. 4).1,40 The combined effects of gravity and the greater tissue mass suspended from a larger dorsal chest wall produce more equal distribution of stress and strain, resulting in more uniform end-expiratory lung volume and alveolar size.

In addition to large-scale ventilation heterogeneity based on gravitational gradients, there is also evidence of heterogeneity among small lung regions in the same gravitational plane. ${ }^{41-44}$ Studies using advanced imaging technology confirmed this finding and demonstrated that the relationship was scale-dependent: Ventilation heterogeneity increased as resolution to detect it increased. ${ }^{14}$ The high degree of ventilation heterogeneity strongly suggested that normal ventilation heterogeneity might have the same fractal characteristics as the initially described heterogeneity of perfusion, which are present in any progressively branching distribution system. ${ }^{45}$ This fractal ventilation hypothesis was confirmed by Altemeier et al, ${ }^{46}$ who dem- 

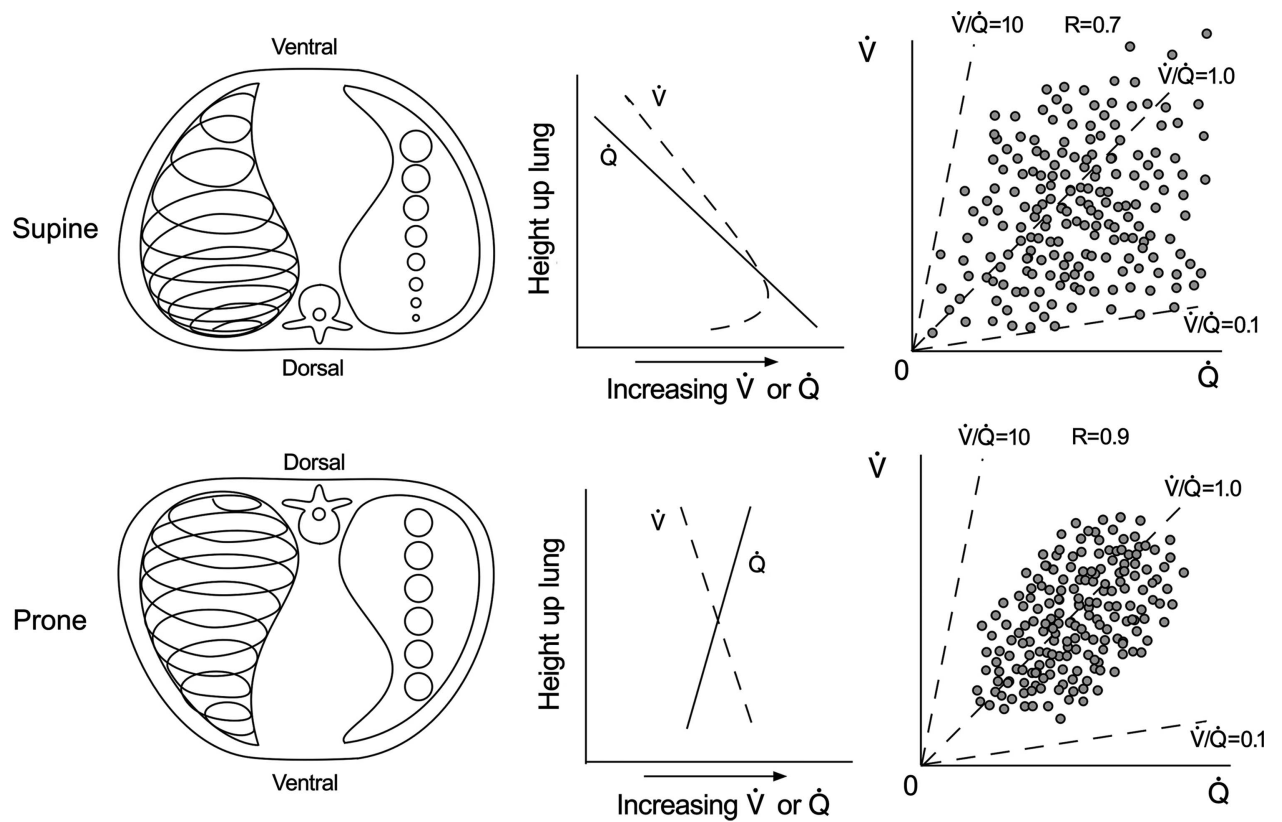

Fig. 4. Distribution of stress and strain and matching of ventilation and perfusion in the supine and prone postures. Considering the lung as a triangular-shaped spring (left), the combined effects of gravity and the greater tissue mass suspended from a larger dorsal chest wall produce more equal distribution of stress and strain in the lung, resulting in more uniform end-expiratory lung volume and alveolar size. On the right, each dot represents a single piece of lung. In the supine posture, there is close matching of ventilation and perfusion in the ventral lung but markedly poor matching in the dorsal lung, resulting a wide distribution of ventilation in perfusion (middle and right). In the supine posture, ventilation and perfusion are more closely matched throughout, resulting in a tighter distribution of ventilation/perfusion ratios.

onstrated that ventilation was distributed in a fractal pattern and that the large range of small-scale differences in ventilation are not randomly scattered but are clustered with adjacent regions having similar ventilation. This smallscale heterogeneity is less likely to be influenced by postural changes.

In summary, ventilation heterogeneity is determined by both large-scale and small-scale factors. Large-scale factors, such as alveolar size, depend on a gravitational pleural pressure gradient that is most pronounced in the upright and supine postures and is less apparent in the prone posture. Heterogeneity also exists among small-isogravitational lung regions, with high-ventilation regions adjacent to other highventilation regions and low-ventilation regions adjacent to other low-ventilation regions following a fractal pattern. The net effect of the prone posture is a more uniform distribution of ventilation.

\section{Spatial Distribution of Perfusion}

Before the mid-1900s, it was thought that blood flow was relatively uniform throughout the lungs. Early studies demonstrated that blood flow was greatest in dependent regions of the lungs and influenced by changes in posture, presumably due to hydrostatic pressure gradients. ${ }^{19,47}$ As the spatial resolution of imaging methods improved, however, the heterogeneity of perfusion became more appar- ent. Studies have demonstrated nearly as much perfusion heterogeneity within isogravitational planes as from the apex to the base of the lung. ${ }^{18,48}$

Perfusion heterogeneity is now known to be influenced by 4 key factors: the hydrostatic gradient induced by gravity and influenced by posture, the local interaction between alveolar and vascular pressures, arteriolar smooth muscle tone, and vascular conductance due the geometry of the vascular tree. ${ }^{18}$ Whereas it has long been recognized that vascular and alveolar pressures interact with gravity to influence blood flow, West et al ${ }^{49}$ proposed the most widely referenced model in which the lung was conceptualized as having 3 vertically arranged zones. Zone 1 represents the apex of the lung, where the alveolar pressure $\left(\mathrm{P}_{\mathrm{A}}\right)$ is greater than arterial $\left(\mathrm{P}_{\mathrm{a}}\right)$ and venous pressure $\left(\mathrm{P}_{\mathrm{v}}\right)$, and, as a result, blood flow is minimal. Zone 2 is the middle portion of the lung, where $\mathrm{P}_{\mathrm{a}}>\mathrm{P}_{\mathrm{A}}>\mathrm{P}_{\mathrm{v}}$ and blood flow is moderate. The base of the lung comprises zone 3 , where $\mathrm{P}_{\mathrm{a}}>\mathrm{P}_{\mathrm{v}}>$ $\mathrm{P}_{\mathrm{A}}$ and blood flow is greatest due to increasing vascular caliber and decreasing vascular resistance.

It was later observed that, even within isogravitational planes, pulmonary blood flow is heterogeneous. ${ }^{50-52}$ Whereas this variability was initially thought to reflect random noise within the observations, in a landmark study, Beck and Rehder ${ }^{53}$ demonstrated that blood flow distribution has a topological pattern independent of gravity. Using microspheres to measure regional blood flow in pump- 
perfused lungs, they found that, regardless of posture or lung volume, blood flow is always greatest in the dorsal region of the lung. This dorsal bias counteracts the effects of gravity in the prone posture, resulting in more uniform blood flow when prone. ${ }^{4,54}$

Subsequent studies confirmed that perfusion heterogeneity favoring the dorsal region is an innate characteristic of the lung, probably related to the geometry of the vascular tree and affected little by changes in posture. ${ }^{18,55-57}$ Insights from fractal geometry probably explain this pattern: Dichotomously branching vascular trees produce heterogeneous distribution of perfusion due to asymmetry in blood flow at branch points. ${ }^{58,59}$ The distribution of blood within isogravitational planes is not random. Instead, similar to the distribution of ventilation, it is spatially organized with high-flow regions near other high-flow regions and low-flow areas neighboring other low-flow areas. ${ }^{60}$ This fractal pattern of perfusion has been demonstrated across a large range of mammals and in various developmental stages and probably accounts for both heterogeneous flow within isogravitational planes as well as the spatial correlation of perfusion across the lung. ${ }^{45,61-67}$

The relative contributions of gravity and vascular geometry to perfusion heterogeneity are dependent on both posture and the scale at which perfusion is observed. ${ }^{18,68}$ Because the vertical hydrostatic gradient is almost double the magnitude in the upright compared with the prone posture in humans, gravity will have a larger contribution to perfusion heterogeneity when upright. If the scale of the observation is the whole lung, variability in perfusion from apex to base will be the sole determinant of perfusion heterogeneity. If the scale is at the level of gas exchange, variability within isogravitational planes becomes predominant. In an attempt to discern the relative contributions of vascular geometry and gravity at the level of gas exchange, the spatial distribution of blood flow in swine was measured during parabolic flight in which gravity can be temporarily abolished or doubled. ${ }^{69}$ Even under markedly different gravitational conditions, high flow lung regions remained high flow, and low flow regions remained low flow, suggesting a greater contribution by vascular geometry (Fig. 5). Subsequent studies using a variety of imaging techniques confirmed this finding. ${ }^{70,71}$ In summary, pulmonary blood flow is influenced by changes in posture due to 2 major factors: hydrostatic pressure due to gravity and conductance of vessels due to geometry. The hydrostatic effect is important in the prone and supine postures, but because of the anatomic differences in conductance due to vascular geometry, pulmonary blood flow favors dorsal regions. These effects balance each other in the prone posture, making perfusion more homogeneous. In the supine posture, both hydrostatic pressure and vascular geometry act to increase flow in the dorsal regions when supine, making perfusion more heterogeneous.

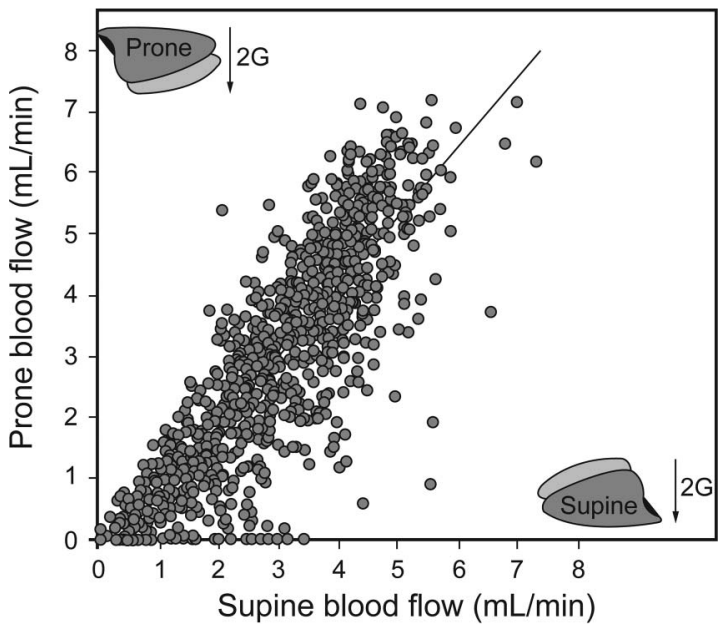

Fig. 5. Blood flow in either $2 \mathrm{G}$ supine or $2 \mathrm{G}$ prone conditions. Each dot represents the amount of blood flow to one of 1,500 lung pieces within the same animal under $2 G$ supine and $2 G$ prone conditions. Note that, independent of gravity and posture, highflow pieces remain high-flow and low-flow pieces remain low-flow. $\mathrm{G}=$ gravitational constant.

\section{Ventilation and Perfusion Matching}

Given that both perfusion and ventilation are heterogeneously distributed, efficient exchange of respiratory gases depends largely on intimate matching of local ventilation and perfusion. In a theoretical analysis, Wilson and Beck ${ }^{6}$ explored the impact of ventilation and perfusion heterogeneity on $\dot{\mathrm{V}}_{\mathrm{A}} / \mathrm{Q}$ inhomogeneity. They demonstrated mathematically that $\dot{\mathrm{V}}_{\mathrm{A}} / \mathrm{Q}$ heterogeneity is related to heterogeneity of ventilation, heterogeneity of perfusion, and the correlation between ventilation and perfusion (Fig. 6). Because the correlation between $\dot{\mathrm{V}}_{\mathrm{A}}$ and $\mathrm{Q}$ varies from complete independence to tight coupling, the heterogeneity of the $\dot{\mathrm{V}}_{\mathrm{A}} / \mathrm{Q}$ distribution varies from a maximum of the sum of the individual variances in both ventilation and perfusion to a perfectly uniform distribution. Hence, regardless of the degree of heterogeneity in $\dot{\mathrm{V}}_{\mathrm{A}}$ or $\dot{\mathrm{Q}}$, tight coupling of $\dot{\mathrm{V}}_{\mathrm{A}}$ and $\dot{\mathrm{Q}}$ creates $\dot{\mathrm{V}}_{\mathrm{A}} / \dot{\mathrm{Q}}$ homogeneity, and the more uniform the $\dot{\mathrm{V}}_{\mathrm{A}} / \mathrm{Q}$ distribution, the better the gas exchange.

Ventilation and perfusion matching occurs via active and passive processes. ${ }^{14,18}$ Active processes include hypoxic pulmonary vasoconstriction, inhalation of nitric oxide from the sinuses, and pneumoconstriction in response to low $\mathrm{P}_{\mathrm{ACO}_{2}}{ }^{18,72-77}$ Of these, the most important is hypoxic pulmonary vasoconstriction, which redistributes blood away from poorly ventilated regions in response to alveolar hypoxia. ${ }^{78-80}$ These active processes have little effect when the $\mathrm{P}_{\mathrm{AO}_{2}}$ is normal but are important in the setting of regional pathology and alveolar hypoxia. ${ }^{78,79,81}$ Passive mechanisms are related to the effect of gravity on ventilation and perfusion distributions, mirroring geome- 

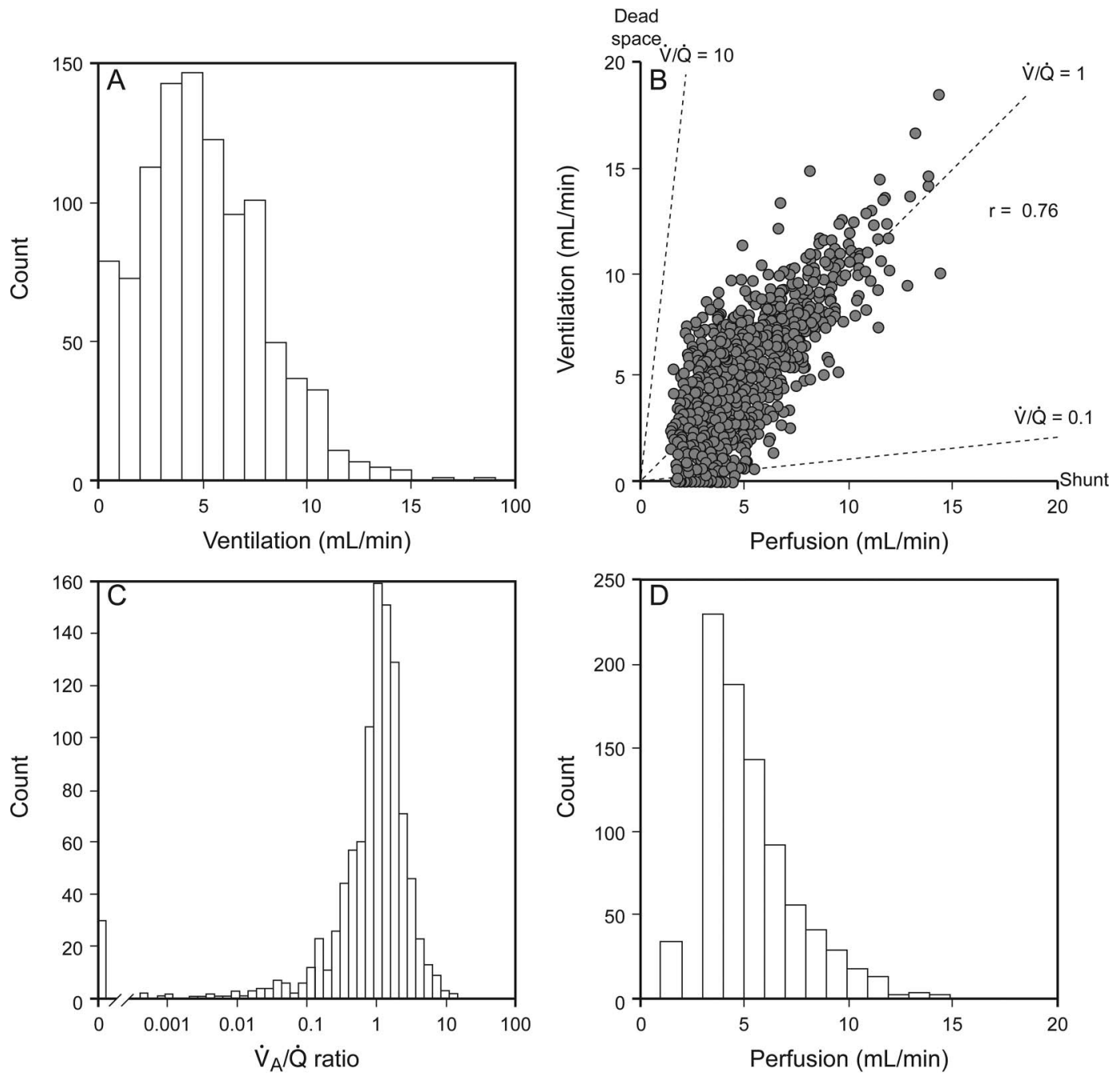

Fig. 6. Depiction of the Wilson and Beck concept. The ventilation and perfusion distribution for 1,024 lung regions are shown in A and D, respectively. Both distributions are heterogeneous and skewed rightward. The correlation between ventilation and perfusion as popularized by Altemeier et al ${ }^{46}$ with alveolar ventilation/perfusion $\left(\dot{V}_{A} / \dot{Q}\right)$ isopleths is shown in $B$. Each dot in this figure represents the ventilation and perfusion to a single piece of lung tissue. Note the regions of shunt along the perfusion axis. The correlation between ventilation and perfusion (0.76 in this example) produces a relatively narrow $\dot{V}_{A} / \dot{Q}$ distribution in $C$. Note the regions of shunt $\left(\dot{V}_{A} / \dot{Q}=0\right)$ in the leftmost portion of this graph.

tries of the airway and vascular trees, and homogenizing effects, such as rebreathing gases from anatomical dead space. ${ }^{82-87}$

Animal data suggest that, in the prone posture, $\dot{V}_{\mathrm{A}}$ and $\dot{Q}$ each individually become more homogeneous, and the correlation between regional $\dot{\mathrm{V}}_{\mathrm{A}}$ and $\mathrm{Q}$ becomes stronger, resulting in improved gas exchange. ${ }^{4,88}$ Using fluorescent aerosols and intravenous microspheres, Mure et al ${ }^{88}$ measured regional ventilation and perfusion in supine and prone swine and found a clear vertical distribution in $\dot{\mathrm{V}}_{\mathrm{A}} / \dot{\mathrm{Q}}$ when supine but not when prone. A study by Treppo et al ${ }^{89}$ also demonstrated that $\dot{Q}$ was found to have a high and significant spatial correlation with $\dot{\mathrm{V}}_{\mathrm{A}}$ in the prone posture, but none in the supine. Similar studies by Altemeier et a ${ }^{90}$ determined that most of the changes in the $\dot{\mathrm{V}}_{\mathrm{A}} / \dot{\mathrm{Q}}$ distribution that occur when changing from the supine to the prone posture are in the dorsocaudal regions, where the lung is compressed in the supine but not the prone posture.

Both regional ventilation and blood flow and the relation between them are also affected by positive-pressure ventilation. During mechanical ventilation of healthy volunteers, for example, the addition of PEEP in the prone posture causes greater redistribution of blood flow than ventilation toward ventral regions of the lung, causing increased $\dot{\mathrm{V}}_{\mathrm{A}} / \mathrm{Q}$ mismatch. ${ }^{91}$ Another study of anesthetized human volunteers demonstrated that the addition of PEEP in the prone posture resulted in a redistribution of blood flow to the ventral lungs with less redistribution of ventilation, leading to increased $\dot{\mathrm{V}}_{\mathrm{A}} / \mathrm{Q}$ mismatch. ${ }^{91}$ With- 
out PEEP, the vertical $\dot{\mathrm{V}}_{\mathrm{A}} / \mathrm{Q}$ gradient was less in the prone posture when compared with the supine..$^{92}$ In contrast, with PEEP, the gradient was similar.

In summary, matching of ventilation and perfusion depends on ventilation and perfusion heterogeneity individually as well as the correlation between them. In the prone posture, both ventilation and perfusion heterogeneity decrease, and the correlation between regional $\dot{\mathrm{V}}_{\mathrm{A}}$ and $\mathrm{Q}$ improves. All 3 of these changes favor improved gas exchange in the normal lung when in the prone posture.

\section{Mechanisms by Which the Prone Posture Improves Gas Exchange in Animal Models of ARDS}

Although improved gas exchange in the prone posture was initially observed in patients with ARDS, animal studies have been instrumental in elucidating some of the mechanisms responsible for better oxygenation. These studies have demonstrated that hypoxemia improves because of reduced venous admixture in the prone posture due to a combination of physiologic changes, including (1) more uniform distribution of ventilation; (2) more uniform distribution of perfusion; (3) better regional matching between ventilation and perfusion; and (4) reduced low$\dot{\mathrm{V}}_{\mathrm{A}} / \mathrm{Q}$ regions. ${ }^{37}$ The mechanisms by which these changes occur are outlined below.

As noted above, the pleural pressure has a smaller vertical gradient at FRC in the prone compared with the supine posture due to shape fitting within the thoracic cavity. ${ }^{93}$ This more uniform pleural pressure gradient results in a more uniform distribution of alveolar volumes at FRC and therefore more uniform distribution of ventilation with inspiration. In ARDS, dependent lung regions become consolidated, increasing the pleural pressure gradient in the supine posture, leading to airway closure and atelectasis at FRC. Due to the loss of surfactant function in ARDS, these collapsed regions are more likely to remain atelectatic throughout the respiratory cycle, a phenomenon that is probably exaggerated when using low-tidal volume ventilation. In addition, the weight of the heart compresses the adjacent lung, leading to more low-ventilation regions. If perfusion persists in these low-ventilation regions, units with low $\dot{\mathrm{V}}_{\mathrm{A}} / \mathrm{Q}$ and even pure shunt are created, leading to hypoxemia. Altemeier et $\mathrm{al}^{90}$ have demonstrated that in pigs without ARDS, the majority of $10 \mathrm{w}-\dot{\mathrm{V}}_{\mathrm{A}} / \mathrm{Q}$ regions exist in the posterior diaphragmatic area and that these regions show the greatest improvement when animals are rotated from the supine to the prone posture. Hypoxic pulmonary vasoconstriction should minimize the impact of these regions on the $\mathrm{P}_{\mathrm{aO}_{2}}$; however, many patients with ARDS have sepsis with inflammatory cytokine or endotoxin that may inhibit hypoxic pulmonary vasoconstriction. ${ }^{94,95}$
Wiener et al ${ }^{96}$ were the first to show in a canine model of ARDS that the vertical gradient of perfusion is less in the prone compared with the supine posture. Whereas they hypothesized that the extravascular lung water in the dependent lung regions would compress the vasculature and redistribute blood flow away from areas of edema, they saw no correlation between regional lung water and blood flow. Richter et al ${ }^{97}$ used a lung lavage model of ARDS in sheep and measured regional perfusion with positron emission tomography. Measurement of a ventral-to-dorsal perfusion gradient demonstrated a significantly lower slope in the prone compared with the supine posture.

Albert et $\mathrm{al}^{37}$ conducted one of the first studies to explore the effect of posture on ventilation/perfusion distributions in a canine ARDS model using the multiple-inert gas elimination technique. They demonstrated that the shunt fraction $\left(\dot{\mathrm{Q}}_{\mathrm{S}} / \dot{\mathrm{Q}}_{\mathrm{T}}\right)$ decreased from a mean of $27.5 \%$ to $13.15 \%$ when animals were changed from the supine to the prone posture. The multiple-inert gas elimination technique does not provide spatial information, and they were not able to conclude how the shunt fraction was reduced. Using a similar oleic acid-induced ARDS model in dogs, Lamm et al ${ }^{98}$ measured regional ventilation and perfusion with single-photon emission tomography, a method that provides spatial information. They found that the ventilation/perfusion ratio gradient from ventral to dorsal was significantly less in the prone posture and that regions of shunt were located in the dorsal lung regions when supine and nearly resolved when turned prone. Whereas these observations can be explained on the basis of improved aeration of the dorsal lung in the prone posture, systemic oxygenation would not improve if blood flow increased to the dependent lung region, as predicted by the gravitational model. In their lung lavage model of ARDS, Richter et $\mathrm{al}^{97}$ found that the dorsal lung regions received most of the blood flow regardless of posture, recapitulating the findings of Beck and Rehder. ${ }^{33}$ The methods used by Richter et al ${ }^{97}$ allowed them to partition the lung into isogravitational planes and measure total perfusion, shunt, total lung volume, and aerated lung (gas volume) in each plane. Graphical representations of their data nicely demonstrate how gas exchange improves in the prone posture in an animal model of ARDS (Fig. 7). The bottom line is that ventilation improves most in the dorsal lung, and blood flow remains greatest in the dorsal lung in the prone posture, thereby improving ventilation-perfusion matching, decreasing venous admixture, and improving oxygenation.

Because shunt physiology, a component of venous admixture, is a major cause of hypoxemia in ARDS, an increase in the mixed venous $\mathrm{O}_{2}$ content will improve arterial oxygenation. Assuming a constant hemoglobin concentration and $\mathrm{O}_{2}$ consumption, the mixed venous 


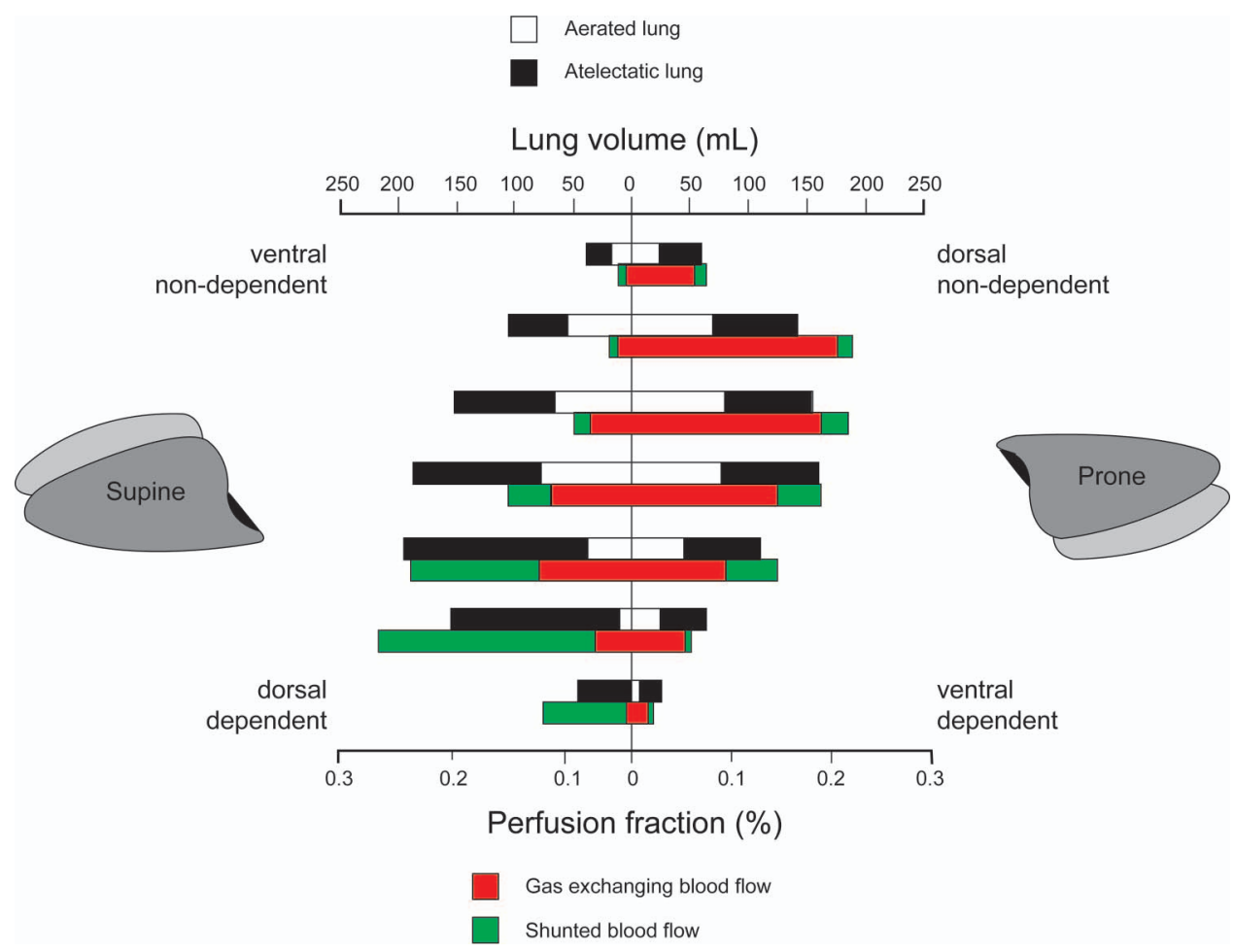

Fig. 7. Lung lavage model of ARDS in sheep that measured regional perfusion and aerated lung with PET. The lungs of each animal were partitioned into 7 isogravitational planes in both supine and prone postures. The lung volume and perfusion fraction in each plane are depicted by the length of the horizontal bars in each posture. Note the large amount of atelectactic lung and the large amount of shunted blood in the dependent lung regions in the supine compared with the prone posture. Also note that there is more blood flow in the non-dependent lung regions in the prone posture. The figure demonstrates that ventilation improves most in the dorsal lung, and blood flow remains greatest in the dorsal lung in the prone posture, thereby decreasing venous admixture and improving gas exchange. Data from Reference 97.

$\mathrm{O}_{2}$ content will increase if cardiac output increases in the prone posture. A clinical study by Blanch et al ${ }^{99}$ did not see any change in cardiac output in the prone posture, whereas a 2013 study in subjects with ARDS demonstrated that cardiac output increases in the prone compared with the supine posture in some subjects. ${ }^{100}$ Interestingly, the subjects noted to have an increased cardiac output did not have a concomitant increase in their mixed venous $\mathrm{P}_{\mathrm{O}_{2}}$. Only a few animal studies of ARDS have measured hemodynamic changes with prone posture. Studies by Albert et $\mathrm{al}^{37}$ and Lamm et al ${ }^{98}$ did not show any differences in cardiac output or mixed venous $\mathrm{P}_{\mathrm{O}_{2}}$ in their canine models, and neither Mure et al ${ }^{88}$ nor Altemeier et al ${ }^{90}$ saw statistically significant changes in cardiac output in their animal studies without lung injury.

$\mathrm{CO}_{2}$ elimination has been noted to improve in the prone posture in patients with ARDS, although this is not a consistent finding across all studies. ${ }^{1,101}$ In fact, an improvement in $\mathrm{P}_{\mathrm{aCO}_{2}}$ when transitioning from the supine to the prone posture has been associated with improved outcome in ARDS subjects. ${ }^{101}$ The mechanism is unknown but has been attributed to decreased dead space ventilation. More likely, the decreased $\mathrm{P}_{\mathrm{aCO}}$ in a patient with unchanged minute ventilation receiving mechanical ventilation is due to the decrease in the venous admixture when turned prone. By decreasing the shunt fraction, less $\mathrm{CO}_{2}$ is delivered to the arterial blood, decreasing the $\mathrm{P}_{\mathrm{aCO}}$. The observation that dead space deceases in the prone posture is due to the use of the Enghoff modification of the Bohr dead space equation, where the $\mathrm{P}_{\mathrm{aCO}_{2}}$ is used as a substitute for the

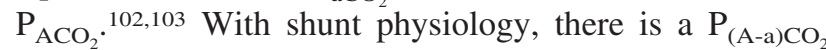
difference, and the $\mathrm{P}_{\mathrm{aCO}}$ is no longer a good estimate of the $\mathrm{P}_{\mathrm{ACO}_{2}}$.

\section{Additional Physiologic Effects of the Prone Posture}

Beyond the alterations in gas exchange described above, ventilation in the prone posture has other physiologic effects that may benefit patients with ARDS. By changing the vertical orientation of the airways, prone posture may prevent pooling of secretions in the base of the lungs and promote secretion clearance. Although changes in secretion volume as a function of posture have not been systematically investigated, clinical studies on the use of prone posture in subjects with ARDS have noted increased se- 


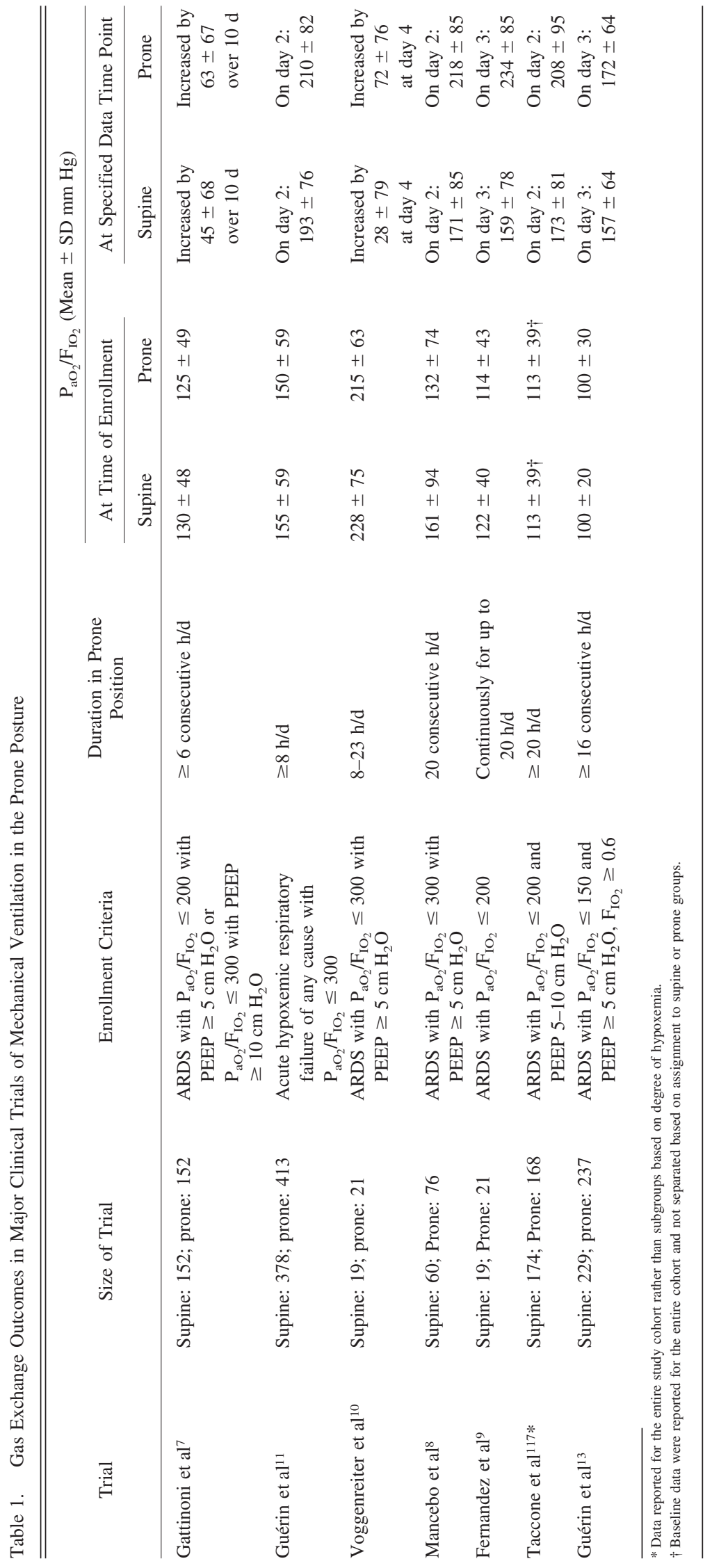


cretion production upon repositioning in this posture. ${ }^{104,105}$ Improved secretion clearance may contribute to improvements in regional ventilation and ventilation-perfusion matching, but whether this translates into a decreased incidence of ventilator-associated pneumonia is unclear because major clinical trials have reported conflicting results in this regard..$^{8,11}$

Ventilation in the prone posture may also promote clearance of edema fluid from the alveolar space in a timedependent manner. McAuley et al, ${ }^{106}$ for example, demonstrated transient increases in extravascular lung water, a surrogate measure of lung edema, after $1 \mathrm{~h}$ of ventilation in the prone position but significant decreases after $18 \mathrm{~h}$. The precise mechanism is not clear but may relate to effects of lung recruitment on alveolar epithelial function, because similar increases in alveolar fluid clearance have also been demonstrated in patients who respond to lung recruitment maneuvers. ${ }^{107}$

Lung injury is heterogeneous in ARDS, and focal areas of consolidation or atelectasis may act as stress multipliers or stress risers, leading to distention and injury of ventilated alveoli. ${ }^{108-110}$ The prone posture may also reduce lung injury by reducing ventilation inhomogeneity.

Another potentially important physiologic effect of prone ventilation is an improvement in right-ventricular function. Acute cor pulmonale may occur in up to $50 \%$ of patients with severe ARDS and may be associated with increased mortality. ${ }^{111,112}$ By increasing the alveolar $\mathrm{P}_{\mathrm{O}_{2}}$ and decreasing $\mathrm{P}_{\mathrm{aCO}_{2}}$ through improved ventilation-perfusion matching and lowering plateau pressure through improved alveolar recruitment, prone ventilation decreases pulmonary vascular resistance and right-ventricular afterload, which have, in turn, been shown to decrease rightventricular enlargement and septal dyskinesia and decrease flow through a patent foramen ovale. ${ }^{111,112,114}$

Finally, by eliminating dependent atelectasis and preventing alveolar collapse at end-exhalation, ventilation in the prone posture can decrease the repetitive opening and closing of alveoli that is thought to contribute to the development of ventilator-induced lung injury through shear forces that increase capillary permeability and trigger inflammatory responses. ${ }^{115,116}$

\section{Clinical Trials}

Beyond the physiologic studies described in detail above, multiple randomized, controlled trials have been conducted to determine whether mechanical ventilation in the prone posture improves clinical outcomes, such as markers of oxygenation, mortality, ICU length of stay, and duration of mechanical ventilation, when compared with ventilation in the supine posture (Table 1).

In the majority of studies, the primary measure of oxygenation is $\mathrm{P}_{\mathrm{aO}_{2}} / \mathrm{F}_{\mathrm{IO}_{2}}$. Some studies also report the alveolar-arterial oxygen difference or the oxygenation index, which is the product of the $\mathrm{F}_{\mathrm{IO}_{2}}$ and mean airway pressure divided by the $\mathrm{P}_{\mathrm{aO}}$.

Regardless of the method for assessing oxygenation, a consistent finding across trials is that prone ventilation is associated with improvements in gas exchange. Despite this consistent result, however, all but one failed to demonstrate a mortality benefit from ventilation in the prone posture. A key feature of the single study to demonstrate improved mortality is that unlike many of the earlier trials, the investigators only included subjects with $\mathrm{P}_{\mathrm{aO}_{2}} / \mathrm{F}_{\mathrm{IO}_{2}} \leq$ 150 , initiated prone positioning within $1 \mathrm{~h}$ of study randomization, and maintained subjects prone for $\geq 16 \mathrm{~h} / \mathrm{d} .{ }^{13}$ Whereas a subsequent systematic review supported the finding that a mortality benefit may be seen in the subgroup of subjects with severe hypoxemia who are placed prone early in their hospital course and for sufficient duration, neither this review nor the study by Guérin et al ${ }^{13}$ established that the improvement in mortality resulted from the improvements in gas exchange rather than some other factor, such as decreased volutrauma. ${ }^{118,119}$ For example, in the study by Guérin et $\mathrm{al}^{13}$ the use of neuromuscular blockade, an intervention shown to improve mortality in a randomized controlled trial of subjects with moderate-tosevere ARDS, was higher in the prone than in the supine group and may have accounted for the mortality benefit rather than the improvement in gas exchange. ${ }^{120}$

\section{Summary}

The effects of the prone posture on gas exchange are many and include a more uniform distribution of ventilation and perfusion along with improved matching of ventilation and blood flow and reduction in regions with low ventilation/perfusion ratios. ${ }^{1,4-6}$ A large randomized trial ${ }^{13}$ has demonstrated that early placement of subjects with moderate-to-severe ARDS in the prone posture improves mortality. The mechanism by which the prone posture confers this mortality benefit is unclear, but it is probably related to reduced stress and strain leading to less lung injury rather than its effects on gas exchange.

\section{REFERENCES}

1. Kallet RH. A comprehensive review of prone position in ARDS. Respir Care 2015;60(11):1660-1687.

2. Piehl MA, Brown RS. Use of extreme position changes in acute respiratory failure. Crit Care Med 1976;4(1):13-14.

3. Douglas WW, Rehder K, Beynen FM, Sessler AD, Marsh HM. Improved oxygenation in patients with acute respiratory failure: the prone position. Am Rev Respir Dis 1977;115(4):559-566.

4. Koulouras V, Papathanakos G, Papathanasiou A, Nakos G. Efficacy of prone position in acute respiratory distress syndrome patients: a pathophysiology-based review. World J Crit Care Med 2016;5(2):121-136. 


\section{Gas Exchange in the Prone Posture}

5. Lee JM, Bae W, Lee YJ, Cho YJ. The efficacy and safety of prone positional ventilation in acute respiratory distress syndrome: updated study-level meta-analysis of 11 randomized controlled trials. Crit Care Med 2014;42(5):1252-1262.

6. Wilson TA, Beck KC. Contributions of ventilation and perfusion inhomogeneities to the $\mathrm{V}_{\mathrm{A}} / \mathrm{Q}$ distribution. J Appl Physiol 1992; 72(6):2298-2304.

7. Gattinoni L, Tognoni G, Pesenti A, Taccone P, Mascheroni D, Labarta V, et al. Effect of prone positioning on the survival of patients with acute respiratory failure. N Engl J Med 2001;345(8): 568-573.

8. Mancebo J, Fernández R, Blanch L, Rialp G, Gordo F, Ferrer M, et al. A multicenter trial of prolonged prone ventilation in severe acute respiratory distress syndrome. Am J Respir Crit Care Med 2006;173(11):1233-1239.

9. Fernandez R, Trenchs X, Klamburg J, Castedo J, Serrano JM, Besso $\mathrm{G}$, et al. Prone positioning in acute respiratory distress syndrome: a multicenter randomized clinical trial. Intensive Care Med 2008; 34(8):1487-1491.

10. Voggenreiter G, Aufmkolk M, Stiletto RJ, Baacke MG, Waydhas $\mathrm{C}$, Ose C. Prone positioning improves oxygenation in post-traumatic lung injury - a prospective randomized trial. J Trauma 2005; 59(2):333-341; discussion 341-343.

11. Guerin C, Gaillard S, Lemasson S, Ayzac L, Girard R, Beuret P, et al. Effects of systematic prone positioning in hypoxemic acute respiratory failure: a randomized controlled trial. JAMA 2004; 292(19):2379-2387.

12. Curley MAQ, Hibberd PL, Fineman LD, Wypij D, Shih MC, Thompson JE, et al. Effect of prone positioning on clinical outcomes in children with acute lung injury: a randomized controlled trial. JAMA 2005;294(2):229-237.

13. Guérin C, Reignier J, Richard JC, Beuret P, Gacouin A, Boulain T, et al. Prone positioning in severe acute respiratory distress syndrome. N Engl J Med 2013;368(23):2159-2168.

14. Petersson J, Glenny RW. Gas exchange and ventilation-perfusion relationships in the lung. Eur Respir J 2014;44(4):1023-1041.

15. Gehr P, Bachofen M, Weibel ER. The normal human lung: ultrastructure and morphometric estimation of diffusion capacity. Respir Physiol 1978;32(2):121-140.

16. Weibel ER, Federspiel WJ, Fryder-Doffey F, Hsia CC, König M, Stalder-Navarro V, Vock R. Morphometric model for pulmonary diffusing capacity. I. Membrane diffusing capacity. Respir Physiol 1993;93(2):125-149.

17. Wagner PD. Ventilation-perfusion matching during exercise. Chest 1992;101(5 Suppl):192S-198S.

18. Glenny RW, Robertson HT. Spatial distribution of ventilation and perfusion: mechanisms and regulation. Compr Physiol 2011;1(1): 375-395.

19. Martin CJ, Cline F Jr, Marshall H. Lobar alvenolar gas concentratoins: effect of body position. J Clin Invest 1953;32(7):617-621.

20. Ball WC Jr, Stewart PB, Newsham LG, Bates DV. Regional pulmonary function studied with xenon 133. J Clin Invest 1962;41: 519-531.

21. Glazier JB, Hughes JM, Maloney JE, West JB. Vertical gradient of alveolar size in lungs of dogs frozen intact. J Appl Physiol 1967; 23(5):694-705

22. Milic-Emili J, Henderson JA, Dolovich MB, Trop D, Kaneko K. Regional distribution of inspired gas in the lung. J Appl Physiol 1966;21(3):749-759.

23. Kaneko K, Milic-Emili J, Dolovich MB, Dawson A, Bates DV. Regional distribution of ventilation and perfusion as a function of body position. J Appl Physiol 1966;21(3):767-777.
24. Brudin LH, Rhodes CG, Valind SO, Jones T, Hughes JM. Interrelationships between regional blood flow, blood volume, and ventilation in supine humans. J Appl Physiol 1994;76(3):1205-1210.

25. Musch G, Layfield JDH, Harris RS, Melo MF, Winkler T, Callahan RJ, et al. Topographical distribution of pulmonary perfusion and ventilation, assessed by PET in supine and prone humans. J Appl Physiol 2002;93(5):1841-1851.

26. Petersson J, Rohdin M, Sánchez-Crespo A, Nyrén S, Jacobsson H, Larsson SA, et al. Posture primarily affects lung tissue distribution with minor effect on blood flow and ventilation. Respir Physiol Neurobiol 2007;156(3):293-303.

27. Amis TC, Jones HA, Hughes JM. Effect of posture on inter-regional distribution of pulmonary ventilation in man. Respir Physiol 1984;56(2):145-167.

28. Hoffman EA. Effect of body orientation on regional lung expansion: a computed tomographic approach. J Appl Physiol 1985;59(2): 468-480.

29. Orphanidou D, Hughes JM, Myers MJ, Al-Suhali AR, Henderson B. Tomography of regional ventilation and perfusion using krypton $81 \mathrm{~m}$ in normal subjects and asthmatic patients. Thorax 1986;41(7): 542-551.

30. Petersson J, Sánchez-Crespo A, Larsson SA, Mure M. Physiological imaging of the lung: single-photon-emission computed tomography (SPECT). J Appl Physiol 2007;102(1):468-476.

31. Tawhai MH, Nash MP, Lin CL, Hoffman EA. Supine and prone differences in regional lung density and pleural pressure gradients in the human lung with constant shape. J Appl Physiol 2009;107(3): 912-920.

32. Guérin C. Prone ventilation in acute respiratory distress syndrome. Eur Respir Rev 2014;23(132):249-257.

33. Gattinoni L, Pelosi P, Vitale G, Pesenti A, D'Andrea L, Mascheroni D. Body position changes redistribute lung computed-tomographic density in patients with acute respiratory failure. Anesthesiology 1991;74(1):15-23

34. Albert RK, Hubmayr RD. The prone position eliminates compression of the lungs by the heart. Am J Respir Crit Care Med 2000; 161(5):1660-1665.

35. Froese AB, Bryan AC. Effects of anesthesia and paralysis on diaphragmatic mechanics in man. Anesthesiology 1974;41(3):242-255.

36. De Keulenaer BL, De Waele JJ, Powell B, Malbrain MLNG. What is normal intra-abdominal pressure and how is it affected by positioning, body mass and positive end-expiratory pressure? Intensive Care Med 2009;35(6):969-976.

37. Albert RK, Leasa D, Sanderson M, Robertson HT, Hlastala MP. The prone position improves arterial oxygenation and reduces shunt in oleic-acid-induced acute lung injury. Am Rev Respir Dis 1987; 135(3):628-633.

38. Chiumello D, Cressoni M, Racagni M, Landi L, Li Bassi G, Polli $\mathrm{F}$, et al. Effects of thoraco-pelvic supports during prone position in patients with acute lung injury/acute respiratory distress syndrome: a physiological study. Crit Care 2006;10(3):R87-

39. Mure M, Glenny RW, Domino KB, Hlastala MP. Pulmonary gas exchange improves in the prone position with abdominal distension. Am J Respir Crit Care Med 1998;157(6 Pt 1):1785-1790.

40. Benson AB, Albert RK. Prone positioning for acute respiratory distress syndrome. Clin Chest Med 2014;35(4):743-752.

41. Engel LA, Utz G, Wood LD, Macklem PT. Ventilation distribution in anatomical lung units. J Appl Physiol 1974;37(2):194-200.

42. Hubmayr RD, Walters BJ, Chevalier PA, Rodarte JR, Olson LE. Topographical distribution of regional lung volume in anesthetized dogs. J Appl Physiol 1983;54(4):1048-1056.

43. Hubmayr RD, Rodarte JR, Walters BJ, Tonelli FM. Regional ventilation during spontaneous breathing and mechanical ventilation in dogs. J Appl Physiol 1987;63(6):2467-2475. 


\section{Gas Exchange in the Prone Posture}

44. Rodarte JR, Chaniotakis M, Wilson TA. Variability of parenchymal expansion measured by computed tomography. J Appl Physiol 1989; 67(1):226-231.

45. Glenny RW, Robertson HT. Fractal properties of pulmonary blood flow: characterization of spatial heterogeneity. J Appl Physiol 1990; 69(2):532-545.

46. Altemeier WA, McKinney S, Glenny RW. Fractal nature of regional ventilation distribution. J Appl Physiol 2000;88(5):15511557.

47. West JB, Dollery CT. Distribution of blood flow and ventilationperfusion ratio in the lung, measured with radioactive carbon dioxide. J Appl Physiol 1960;15:405-410.

48. Glenny RW, Polissar L, Robertson HT. Relative contribution of gravity to pulmonary perfusion heterogeneity. J Appl Physiol 1991; 71(6):2449-2452.

49. West JB, Dollery CT, Naimark A. Distribution of blood flow in isolated lung: relation to vascular and alveolar pressures. J Appl Physiol 1964;19:713-724.

50. Reed JH Jr, Wood EH. Effect of body position on vertical distribution of pulmonary blood flow. J Appl Physiol 1970;28(3):303311.

51. Melsom MN, Flatebø T, Kramer-Johansen J, Aulie A, Sjaastad OV, Iversen PO, Nicolaysen G. Both gravity and non-gravity dependent factors determine regional blood flow within the goat lung. Acta Physiol Scand 1995;153(4):343-353.

52. Greenleaf JF, Ritman EL, Sass DJ, Wood EH. Spatial distribution of pulmonary blood flow in dogs in left decubitus position. Am J Physiol 1974;227(1):230-244.

53. Beck KC, Rehder K. Differences in regional vascular conductances in isolated dog lungs. J Appl Physiol 1986;61(2):530-538.

54. Nyrén S, Mure M, Jacobsson H, Larsson SA, Lindahl SGE. Pulmonary perfusion is more uniform in the prone than in the supine position: scintigraphy in healthy humans. J Appl Physiol 1999;86(4):1135-1141.

55. Glenny RW, Lamm WJ, Albert RK, Robertson HT. Gravity is a minor determinant of pulmonary blood flow distribution. J Appl Physiol 1991;71(2):620-629.

56. Glenny RW, Robertson HT. A computer simulation of pulmonary perfusion in three dimensions. J Appl Physiol 1995;79(1):357-369.

57. Bernard SL, Glenny RW, Erickson HH, et al. Minimal redistribution of pulmonary blood flow with exercise in racehorses. J Appl Physiol 1996;81(3):1062-1070.

58. Mandelbrot BB. The Fractal Geometry of Nature. San Francisco: Freeman; 1983.

59. Van Beek JH, Roger SA, Bassingthwaighte JB. Regional myocardial flow heterogeneity explained with fractal networks. Am J Physiol 1989;257(5 Pt 2):H1670-H1680.

60. Glenny RW. Spatial correlation of regional pulmonary perfusion. J Appl Physiol 1992;72(6):2378-2386.

61. West GB, Brown JH, Enquist BJ. The fourth dimension of life: fractal geometry and allometric scaling of organisms. Science 1999; 284(5420):1677-1679.

62. Sinclair SE, McKinney S, Glenny RW, Bernard SL, Hlastala MP. Exercise alters fractal dimension and spatial correlation of pulmonary blood flow in the horse. J Appl Physiol 2000;88(6):2269-2278.

63. Parker JC, Ardell JL, Hamm CR, Barman SA, Coker PJ. Regional pulmonary blood flow during rest, tilt, and exercise in unanesthetized dogs. J Appl Physiol 1995;78(3):838-846.

64. Glenny RW, McKinney S, Robertson HT. Spatial pattern of pulmonary blood flow distribution is stable over days. J Appl Physiol 1997;82(3):902-907.

65. Glenny RW, Bernard SL, Robertson HT. Pulmonary blood flow remains fractal down to the level of gas exchange. J Appl Physiol 2000;89(2):742-748.
66. Glenny RW, Bernard SL, Luchtel DL, Neradilek B, Polissar NL. The spatial-temporal redistribution of pulmonary blood flow with postnatal growth. J Appl Physiol 2007;102(3):1281-1288.

67. Caruthers SD, Harris TR. Effects of pulmonary blood flow on the fractal nature of flow heterogeneity in sheep lungs. J Appl Physiol 1994;77(3):1474-1479.

68. Glenny R. Counterpoint: Gravity is not the major factor determining the distribution of blood flow in the healthy human lung. J Appl Physiol 2008;104(5):1533-1555; discussion 1535-1536.

69. Glenny RW, Lamm WJ, Bernard SL, An D, Chornuk M, Pool SL, et al. Selected contribution: redistribution of pulmonary perfusion during weightlessness and increased gravity. J Appl Physiol 2000; 89(3):1239-1248.

70. Burrowes KS, Tawhai MH. Computational predictions of pulmonary blood flow gradients: gravity versus structure. Respir Physiol Neurobiol 2006;154(3):515-523.

71. Hopkins SR, Henderson AC, Levin DL, Yamada K, Arai T, Buxton RB, Prisk GK. Vertical gradients in regional lung density and perfusion in the supine human lung: the Slinky effect. J Appl Physiol 2007;103(1):240-248.

72. Lundberg JO, Lundberg JM, Settergren G, Alving K, Weitzberg E. Nitric oxide, produced in the upper airways, may act in an "aerocrine" fashion to enhance pulmonary oxygen uptake in humans. Acta Physiol Scand 1995;155(4):467-468.

73. Emery MJ, Eveland RL, Kim SS, Hildebrandt J, Swenson ER. $\mathrm{CO}_{2}$ relaxes parenchyma in the liquid-filled rat lung. J Appl Physiol 2007;103(2):710-716.

74. D'Angelo E, Calderini IS, Tavola M. The effects of $\mathrm{CO}_{2}$ on respiratory mechanics in anesthetized paralyzed humans. Anesthesiology 2001;94(4):604-610.

75. Duke HN, Killick EM. Pulmonary vasomotor responses of isolated perfused cat lungs to anoxia. J Physiol 1952;117(3):303-316.

76. Barer GR, Shaw JW. Pulmonary vasodilator and vasoconstrictor actions of carbon dioxide. J Physiol 1971;213(3):633-645.

77. Barer GR, Howard P, Shaw JW. Sensitivity of pulmonary vessels to hypoxia and hypercapnia. J Physiol 1970;206(2):25P-26P.

78. Sylvester JT, Shimoda LA, Aaronson PI, Ward JPT. Hypoxic pulmonary vasoconstriction. Physiol Rev 2012;92(1):367-520.

79. Naeije R, Brimioulle S. Physiology in medicine: importance of hypoxic pulmonary vasoconstriction in maintaining arterial oxygenation during acute respiratory failure. Crit Care 2001;5(2):6771.

80. Morrell NW, Nijran KS, Biggs T, Seed WA. Magnitude and time course of acute hypoxic pulmonary vasoconstriction in man. Respir Physiol 1995;100(3):271-281.

81. Arai TJ, Henderson AC, Dubowitz DJ, Levin DL, Friedman PJ, Buxton RB, et al. Hypoxic pulmonary vasoconstriction does not contribute to pulmonary blood flow heterogeneity in normoxia in normal supine humans. J Appl Physiol 2009;106(4):1057-1064.

82. West JB. Regional differences in gas exchange in the lung of erect man. J Appl Physiol 1962;17:893-898.

83. Weibel ER, Sapoval B, Filoche M. Design of peripheral airways for efficient gas exchange. Respir Physiol Neurobiol 2005;148(1):3-21.

84. Weibel ER, Taylor CR, Hoppeler H. The concept of symmorphosis: a testable hypothesis of structure-function relationship. Proc Natl Acad Sci USA 1991;88(22):10357-10361.

85. Blank R, Napolitano LM. Epidemiology of ARDS and ALI. Crit Care Clin 2011;27(3):439-458.

86. Ross BB, Farhi LE. Dead-space ventilation as a determinant in the ventilation-perfusion concept. J Appl Physiol 1960;15:363-371.

87. Tsukimoto K, Arcos JP, Schaffartzik W, Wagner PD, West JB. Effect of common dead space on $\mathrm{V}_{\mathrm{A}} / \mathrm{Q}$ distribution in the dog. J Appl Physiol 1990;68(6):2488-2493. 


\section{Gas Exchange in the Prone Posture}

88. Mure M, Domino KB, Lindahl SGE, Hlastala MP, Altemeier WA, Glenny RW. Regional ventilation-perfusion distribution is more uniform in the prone position. J Appl Physiol 2000;88(3):10761083.

89. Treppo S, Mijailovich SM, Venegas JG. Contributions of pulmonary perfusion and ventilation to heterogeneity in $\mathrm{V}(\mathrm{A}) / \mathrm{Q}$ measured by PET. J Appl Physiol 1997;82(4):1163-1176.

90. Altemeier WA, McKinney S, Krueger M, Glenny RW. Effect of posture on regional gas exchange in pigs. J Appl Physiol 2004; 97(6):2104-2111.

91. Petersson J, Ax M, Frey J, Sánchez-Crespo A, Lindahl SGE, Mure M. Positive end-expiratory pressure redistributes regional blood flow and ventilation differently in supine and prone humans. Anesthesiology 2010;113(6):1361-1369.

92. Walther SM, Domino KB, Glenny RW, Hlastala MP. Pulmonary blood flow distribution in sheep: effects of anesthesia, mechanical ventilation, and change in posture. Anesthesiology 1997;87(2):335342 .

93. Mutoh T, Guest RJ, Lamm WJ, Albert RK. Prone position alters the effect of volume overload on regional pleural pressures and improves hypoxemia in pigs in vivo. Am Rev Respir Dis 1992;146(2): 300-306.

94. Gerbino AJ, McKinney S, Glenny RW. Correlation between ventilation and perfusion determines $\mathrm{V}_{\mathrm{A}} / \mathrm{Q}$ heterogeneity in endotoxemia. J Appl Physiol 2000;88(6):1933-1942.

95. Pandolfi R, Barreira B, Moreno E, Lara-Acedo V, Morales-Cano D, Martínez-Ramas A, et al. Role of acid sphingomyelinase and IL-6 as mediators of endotoxin-induced pulmonary vascular dysfunction. Thorax 2017;72(5):460-471.

96. Wiener CM, Kirk W, Albert RK. Prone position reverses gravitational distribution of perfusion in dog lungs with oleic acid-induced injury. J Appl Physiol 1990;68(4):1386-1392.

97. Richter T, Bellani G, Scott Harris R, Vidal Melo MF, Winkler T, Venegas JG, Musch G. Effect of prone position on regional shunt, aeration, and perfusion in experimental acute lung injury. Am J Respir Crit Care Med 2005;172(4):480-487.

98. Lamm WJ, Graham MM, Albert RK. Mechanism by which the prone position improves oxygenation in acute lung injury. Am J Respir Crit Care Med 1994;150(1):184-193.

99. Blanch L, Mancebo J, Perez M, Martinez M, Mas A, Betbese AJ, et al. Short-term effects of prone position in critically ill patients with acute respiratory distress syndrome. Intensive Care Med 1997; 23(10):1033-1039.

100. Jozwiak M, Teboul JL, Anguel N, Persichini R, Silva S, Chemla D, et al. Beneficial hemodynamic effects of prone positioning in patients with acute respiratory distress syndrome. Am J Respir Crit Care Med 2013;188(12):1428-1433.

101. Gattinoni L, Vagginelli F, Carlesso E, Taccone P, Conte V, Chiumello D, et al. Decrease in $\mathrm{P}_{\mathrm{aCO}}$ with prone position is predictive of improved outcome in acute respiratory distress syndrome. Crit Care Med 2003;31(12):2727-2733.

102. Robertson HT. Dead space: the physiology of wasted ventilation. Eur Respir J 2015;45(6):1704-1716.

103. Robertson HT, Swenson ER. What do dead-space measurements tell us about the lung with acute respiratory distress syndrome? Respir Care 2004;49(9):1006-1007.
104. Chatte G, Sab JM, Dubois JM, Sirodot M, Gaussorgues P, Robert D. Prone position in mechanically ventilated patients with severe acute respiratory failure. Am J Respir Crit Care Med 1997;155(2): 473-478.

105. Langer M, Mascheroni D, Marcolin R, Gattinoni L. The prone position in ARDS patients: a clinical study. Chest 1988;94(1):103107.

106. McAuley DF, Giles S, Fichter H, Perkins GD, Gao F. What is the optimal duration of ventilation in the prone position in acute lung injury and acute respiratory distress syndrome? Intensive Care Med 2002;28(4):414-418.

107. Constantin JM, Cayot-Constantin S, Roszyk L, Futier E, Sapin V, Dastugue B, et al. Response to recruitment maneuver influences net alveolar fluid clearance in acute respiratory distress syndrome. Anesthesiology 2007;106(5):944-951.

108. Gattinoni L, Quintel M. How ARDS should be treated. Crit Care 2016;20:86.

109. Cressoni M, Cadringher P, Chiurazzi C, Amini M, Gallazzi E, Marino A, et al. Lung inhomogeneity in patients with acute respiratory distress syndrome. Am J Respir Crit Care Med 2014;189(2): 149-158.

110. Mead J, Takishima T, Leith D. Stress distribution in lungs: a model of pulmonary elasticity. J Appl Physiol 1970;28(5):596-608.

111. Vieillard-Baron A, Charron C, Caille V, Belliard G, Page B, Jardin F. Prone positioning unloads the right ventricle in severe ARDS. Chest 2007;132(5):1440-1446.

112. Boissier F, Katsahian S, Razazi K, Thille AW, Roche-Campo F, Leon R, et al. Prevalence and prognosis of cor pulmonale during protective ventilation for acute respiratory distress syndrome. Intensive Care Med 2013;39(10):1725-1733

113. Repessé X, Charron C, Vieillard-Baron A. Acute cor pulmonale in ARDS: rationale for protecting the right ventricle. Chest 2015; 147(1):259-265.

114. Legras A, Dequin PF, Hazouard E, Doucet O, Tranquart F, Perrotin D. Right-to-left interatrial shunt in ARDS: dramatic improvement in prone position. Intensive Care Med 1999;25(4):412-414.

115. Broccard A, Shapiro RS, Schmitz LL, Adams AB, Nahum A, Marini JJ. Prone positioning attenuates and redistributes ventilator-induced lung injury in dogs. Crit Care Med 2000;28(2):295-303.

116. Broccard AF, Shapiro RS, Schmitz LL, Ravenscraft SA, Marini JJ. Influence of prone position on the extent and distribution of lung injury in a high tidal volume oleic acid model of acute respiratory distress syndrome. Crit Care Med 1997;25(1):16-27.

117. Taccone P, Pesenti A, Latini R, Polli F, Vagginelli F, Mietto C, et al. Prone positioning in patients with moderate and severe acute respiratory distress syndrome: a randomized controlled trial. JAMA 2009;302(18):1977-1984.

118. Albert RK, Keniston A, Baboi L, Ayzac L, Guérin C, Proseva Investigators. Prone position-induced improvement in gas exchange does not predict improved survival in the acute respiratory distress syndrome. Am J Respir Crit Care Med 2014;189(4):494-496.

119. Bloomfield R, Noble DW, Sudlow A. Prone position for acute respiratory failure in adults. Cochrane Database Syst Rev 2015; (11):CD008095

120. Papazian L, Forel JM, Gacouin A, Penot-Ragon C, Perrin G, Loundou A, et al. Neuromuscular blockers in early acute respiratory distress syndrome. N Engl J Med 2010;363(12):1107-1116. 